\title{
IDENTIFIKASI ARAH PERSEBARAN SEDIMENTASI MENGGUNAKAN ANALISIS MIKROTREMOR STUDI KASUS KAWASAN SUMUR TUA KECAMATAN WRINGINANOM, GRESIK
}

\author{
Muhammad Fikri Putra P, Nizar Dwi Riyantiyo, Muhammad Reza Shalahuddin Noor, Dwa Desa Warnana, Firman \\ Syaifuddin, Wien Lestari, Juan Pandu Gya Nur Rochman, Anik Hilyah \\ Departemen Teknik Geofisika, Fakultas Teknik Sipil dan Perencanaan, Institut Teknologi Sepuluh Nopember \\ Email : fikriputrap@gmail.com
}

\begin{abstract}
Abstrak. Jawa timur bagian utara merupakan daerah prospek dalam industri Minyak dan Gas Bumi. Sebagai zona RMKS (Rembang, Madura, Kangean, dan Subala). Cekungan Jawa Timur utara memiliki kerangka geologi didominasi oleh graben, half-graben, dan sesar lain akibat fase rifting pada periode ekstensional zaman Paleogen dan arah sedimentasi berawal sisi utara cekungan, seiring terbentuknya gunung api hasil subduksi lempeng dibagian selatan maka sedimen terendapkan dari bagian selatan cekungan. Secara regional terdapat potensi reservoar yang terbentuk dari batuan pasir dan karbonat. Berlatarbelakang sumur tua yang terletak di desa Sumberwaru, Kecamatan Wringinanom, Gresik. Indikasi awal daerah tersebut memiliki petroleum system sehingga, penelitian bertujuan mengidentifikasi arah persebaran sedimen dalam tinjauan awal eksplorasi kembali pada daerah tersebut. Data yang digunakan adalah data primer pengukuran metode mikrotremor berdimensi $36.000 \mathrm{~m}^{2}$ (122 titik) selama 6 hari, dengan frekuensi natural 4-8 Hz.
\end{abstract}

Kata Kunci : Mikrotremor, frekuensi, HVSR, Vs30, Wringinanom

\begin{abstract}
East Java is the northern region of prospect in the Oil and Gas industry. As a zone of RMKS (Rembang, Madura, Kangean, and Subala). The northern East Java basin has a geological framework dominated by graben, half-graben and other faults due to the rifting phase of the Paleogenian period and the sedimentation direction begins on the north side of the basin, as the resulting volcanic subduction volcano in the southern part of the sediment is deposited from the southern part of the basin. Regionally there are reservoir potentials formed from sand and carbonate rocks. Background of the old well located in the village Sumberwaru, District Wringinanom, Gresik. The initial indication of the area has a petroleum system so that, the study aims to identify the direction of the distribution of sediments in the initial review of re-exploration of the area. The data used is the primary data measuring mikrotremor method dimension $36.000 \mathrm{~m}^{2}$ (122 point) for 6 days, with natural frequency $4-8 \mathrm{~Hz}$.
\end{abstract}

Keywords: Microtremor, frequency, HVSR, Vs30, Wringinanom

\section{PENDAHULUAN}

Jawa Timur merupakan daerah prospek sebagai lapangan industri Minyak dan Gas. Dengan kerangka tektonik pembentuk zona rifting dan lipatan dibagian utara, maka pada penelitian ini bertujuan untuk meninjau kembali penebalan sedimentasi pada kawasan pasca ekploitasi Minyak dan Gas di Kecamatan Wringinanom, Gresik. Sehingga penelitian ini bertujuan sebagai tinjauan awal perencanaan ekplorasi kembali pada kawasan tersebut.

Studi geologi regional di wilayah penelitian dilakukan empat lokasi penelitian, dari keseluruhan lokasi didominasi oleh jenis batuan sedimen (Gambar 1). Geologi Regional kawasan penelitian didominasi perlapisan litologi batu pasir, lanau, sisipan batu gamping, dan batu lempung. dengan tebal lapisan 30-50 cm (Gambar 2).. Struktur patahan turun dengan orientasi Barat-Timur dan sayap antiklin dengan orientasi anticlinorium berarah
Barat-Timur. Tinjauan geologi ini diintergrasikan dengan peta geologi Surabaya-Sapulu, dimana daerah penelitian didominasi litologi batu pasir berasal dari formasi Pucangan dengan bagian bawah pasir tufan berlapis baik, bersisipan konglomerat batu lempung dan kaya fosil moluska serta plankton. Akan tetapi hasil integrasi peta geologi kawasan penelitian berada pada formasi Lidah dengan litologi penyusun berupa lempung biru miskin fosil dengan lensa tipis lempung pasiran.

Metode Mikrotremor adalah salah satu metode pasif geofisika yang memanfaatkan getaran natural yang dihasilkan bumi. Sehingga frekuensi dominan yang dihasilkan, sehingga dapat merepresentasikan ketebalan lapisan dengan karakteristik sedimen lunak diatas batuan keras atau bed rock (Arwananda et al., 2017; Sitorus et al., 2017; Sutrisna, et al., 2015; Syaifuddin et al., 2016). 


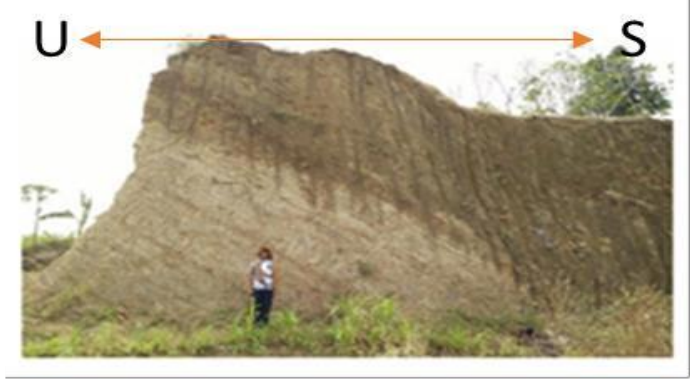

Gambar 1. Sayap Antiklin dengan strike N60E/30

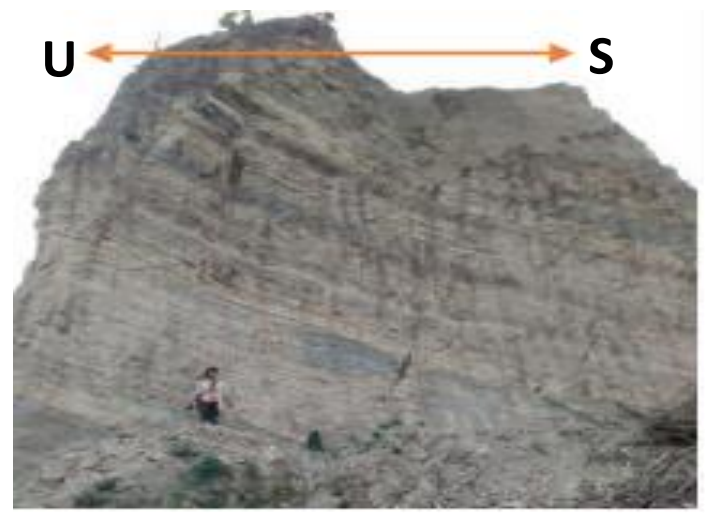

Gambar 2. Sayap Antiklin dengan strike N225E/30

\section{METODOLOGI}

Metode HVSR diperkenalkan pertama kali oleh Nakamura (1989), digunakan untuk mengestimasi frekuensi natural dan amplifikasi geologi setempat dari data mikrotremor dan metode ini berkembang dapat mengestimasi nilai kerentanan daerah pengukuran. Metode HVSR didasari oleh terperangkapnya gelombang geser pada medium sedimen diatas bedrock.

$$
f=\frac{V_{s}}{4 h}
$$

Dengan Vs adalah kecepatan gelombang geser dan $h$ mewakili kedalaman bedrock.

\section{Perhitungan ketebalan sedimen}

Dalam penelitian ini dihitung ketebalan sedimen dengan mencari nilai Vs30 yang dapat dicari melalui web

\section{HASIL DAN PEMBAHASAN}

Hasil pengolahan yang didapatkan berupa grafik Horizontal to Vertikal (H/V), merupakan hasil Fast Fourier Transform (FFT) dari data yang didapatkan dan didalam grafik tersebut memuat informasi frekuensi dominan dan amplifikasi.
USGS, sesuai lokasi peneitian, untuk perhitungan secara matematisnya seperti berikut,

$$
h=\frac{\text { Veao }}{4 f_{0}}
$$

Dengan nilai $\mathrm{h}$ merupakan kedalaman sedimen, Vs30 kecepatan geser pada kedalaman 30 meter, dan fo merupakan frekuensi natural pada lokasi penelitian.

\section{Metode Penelitian}

Penelitian ini digunakan metode mikrotremor tipe MAE dan SARA, pengukuran didasari desain akuisisi dengan luas 36.000 m2 (122 titik) selama 6 hari Penelitian melakukan beberapa hal yang harus diperhatikan seperti kondisi tanah saat pegukuran (keras atau lunak), kondisi vegetasi dan permukaan daerah penelitian. Serta perlu adanya catatan indikasi penyebab noise dalam hal ini, adanya aktivitas yang dilakukan manusia, sehingga memudahkan dalam proses pengolahan data.

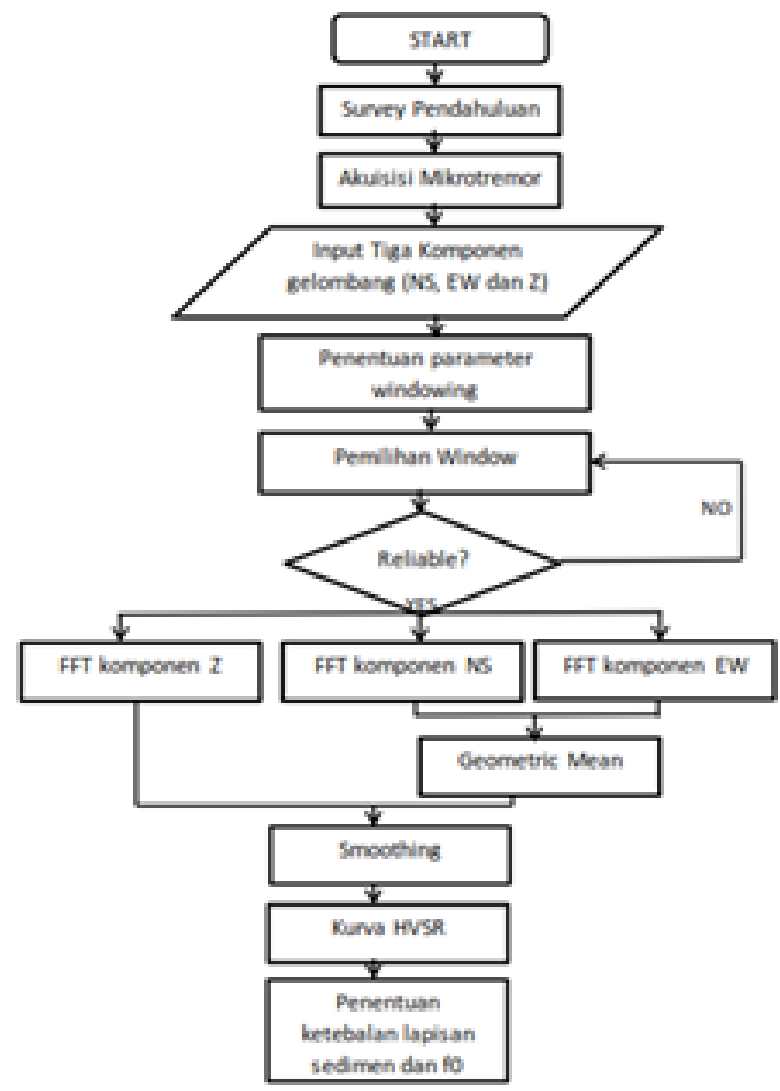

Gambar 3. Metodologi Penelitian 


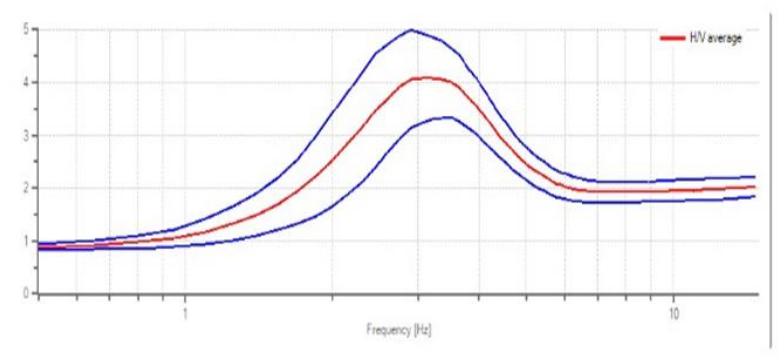

Gambar 4. Kurva H/V, dengan sumbu Y merupakan nilai $\mathrm{H} / \mathrm{V}$ (Amplifikasi), sumbu $\mathrm{X}$ merupakan nilai frekuensi, dan garis berwarna merah merepresentasikan $\mathrm{H} / \mathrm{V}$ ratarata.

Hasil dari pengolahan data mikrotremor adalah nilai dari frekuensi dominan pada area penelitian, sehingga didapatkan nilai frekuensi dominan dari grid pengukuran, dan diplotkan dalam sebuah peta kontur frekuensi dominan dan ketebalan sedimen. Nilai frekuensi natural dapat merepresentasikan nilai dari ketebalan sedimen di kecamatan Wringinanom, Gresik, Jawa Timur. Dengan nilai frekuensi natural 1-9 Hz, nilai frekuensi dominan akan berbanding terbalik dengan nilai ketebalan sedimentasi.

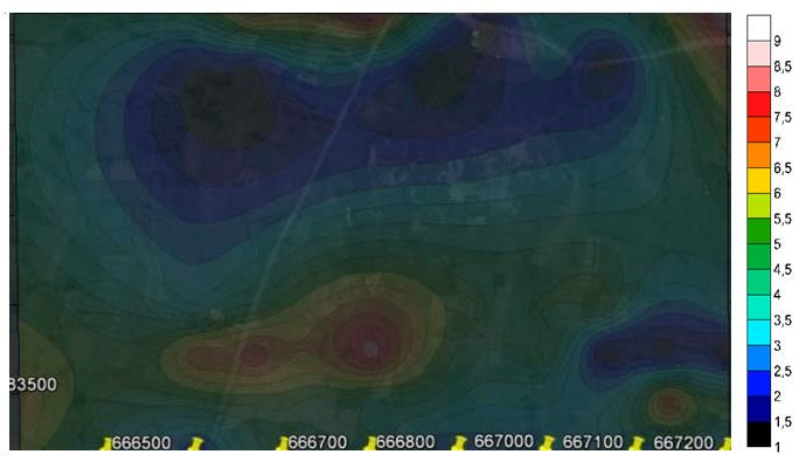

Gambar 5. Kontur frekuensi natural. Nilai X dan Y merupakan koordinat titik pengukuran dan warna merepresentasikan frekuensi natural.

Untuk melakukan analisis lebih lanjut mengenai nilai ketebalan sedimen yang ada di kecamatan Wringinanom, dilakukan pendekatan Vertical Electrical Sounding (VES) dan seismik refraksi untuk mendapatkan nilai Vs30. Kemudian dilakukan perhitungan sesuai persamaan (2) untuk mendapatkan nilai ketebalan sedimen wilayah peneitian.

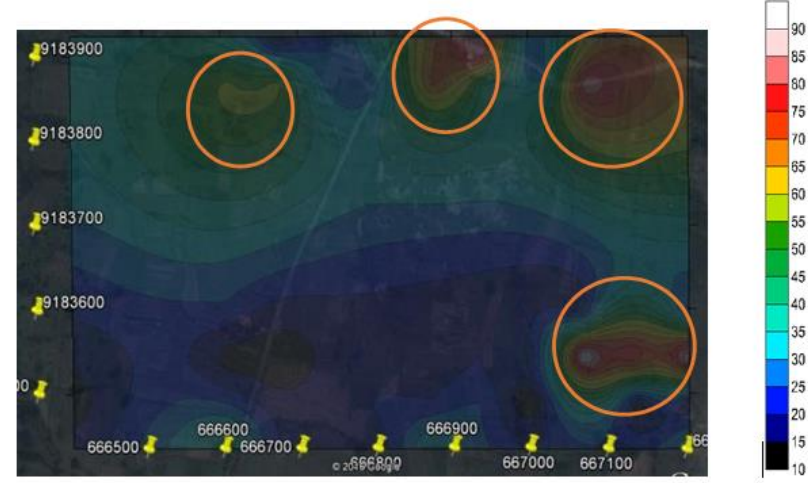

Gambar 6. Kontur kedalaman sedimentasi, lingkaran berwarna merah merupakan daerah yang memiliki endapan sedimen lebih tebal.

Dari hasil kontur didapatkan kedalaman sedimen kecamatan Wringinanom berkisar 10-90 meter. Dari kontur pada gambar 8 , terlihat penebalan sedimen mengindikasikan struktur puncak antiklin dengan arah pesebaran sedimentasi dari arah utara ke selatan.

Apabila dalam industri migas metode yang efektif untuk melihat struktur bawah permukaan adalah seismik refleksi, dengan adanya sedimen yang tebal dapat mempengaruhi kualitas data sesimik. Gelombang cenderung terabsorbsi oleh lapisan lunak dan berongga, sehingga hasil dari penelitian ini merekomendasikan untuk dilakukannya eksplorasi kembali pada bagian utara lokasi penelitian dan bagian selatan penelitian dengan nilai ketebalan sedimen 10-30 meter.

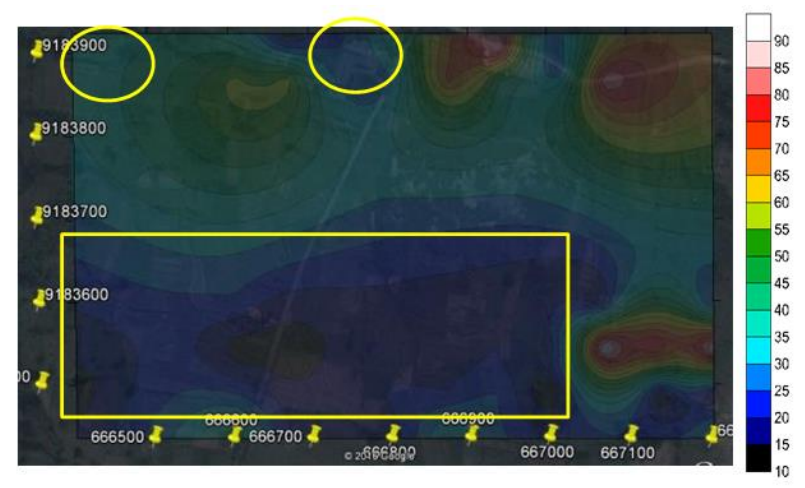

Gambar 7. Tanda kuning merupakan lokasi rekomendasi dilakukan penelitian lebih lanjut. 


\section{Simpulan}

Dari hasil penelitian yang dilakukan, diperoleh nilai frekuensi dominan $1-9 \mathrm{~Hz}$. Kemudian dalam menentukan ketebalan sedimen dilakukan pendekatan seismik refraksi dan VES untuk menentukan nilai Vs30, sehingga didapatkan nilai ketebalan sedimen 10-60 meter. Ketika medium sedimen dilewatkan gelombang nilai amplifikasi akan menjadi besar, dengan karakter batuan sedimen yang lunak akan lebih destruktif dibandingkan batuan yang lebih kompak dan nilai lapisan sedimen lapuk yang tebal akan menyebabkan peluruhan energi gelombang. Sehingga dari hasil penelitian dapat ditentukan rekomendasi yanng perlu dilakukan penelitian lebih lanjut menggunakan metode seismik refleksi sehingga peningkatan resolusi seismik, dan juga dapat memperkirakan zona rawan destruktif pada wilayah penelitian.

\section{Saran}

Perlu dilakukan uji SPT untuk memastikan lebih lanjut mengenai arah sedimentasi pada titik titik prospek dan pengukuran geofisika untuk memvisualisasikan struktur bawah permukaan di daerah penelitian.

\section{Ucapan Terimakasih}

Terimakasih kepada teman-teman TG 2013 yang telah membantu dalam proses akuisisi data. Kepada bapak dan ibu dosen yang telah membimbing dan memberi dukungan moril kepada penulis sehingga penelitian dapat terselesaikan. Semoga peneltian ini dapat bermanfaat.

\section{DAFTAR PUSTAKA}

Arwananda, A.P., Aryaseta, B., Dezulfakar, H., Fatahillah, Y., Rochman, J.P.G.N., 2017. Horizontal-vertical Spectral Ratio Method in Microtremor to Estimate Engineering Bedrock Thickness at Sedati Mud Volcano. IOP Conf. Ser. Earth Environ. Sci. 62, 012010. https://doi.org/10.1088/1755$\underline{1315 / 62 / 1 / 012010}$

Badan Geologi - Kementrian Energi dan Sumber Daya Mineral. 2015. Mikrozonasi Bahaya Gempa Mataram. GEOMAGZ Majalah Geologi Populer Vol. $5 B$

E. Soebowo, A. Tohari, Y. Kumoro, M.R Daryono. 2009. Sifat Keteknikan Bawah Permukaan di Daerah Pesisir Cilacap, Provinsi Jawa Tengah. Bulletin Geologi Tata Lingkungan, Vol. 19.

Nakamura, Y. 1989. A Method For Dynamic Characteristics Estimation of Subsurface Using Microtremor On The Ground Surface. Quarterly report of Railway Technical Research Institute.
Sutrisna, Ma'sum, Cecep Sulaeman, dan Nanang Dwi Ardi. 2015. Metode Mikrotremor Untuk Mikrozonasi Gempa Bumi Di Kota Cilacap. Deptartemen Pendidikan Fisika, Fakultas Pendidikan Matematika dan IImu Pengetahuan Alam : Universitas Pendidikan Indonesia.

Sitorus, N., Purwanto, S., Utama, W., 2017. Analisis Nilai Frekuensi Natural dan Amplifikasi Desa Olak Alen Blitar Menggunakan Metode Mikrotremor HVSR. J. Geosaintek3,89-92.

https://doi.org/10.12962/i25023659.v3i2.2962

Syaifuddin, F., Bahri, A.S., Lestari, W., Pandu, J., 2016. Microtremor study of Gunung Anyar mud volcano, Surabaya, East Java. AIP Conf. Proc.1730,050004.https://doi.org/10.1063/1.

Z Herman. 2005. Kegiatan Pemantauan Dan Evaluasi Konservasi Sumber daya Mineral Daerah Kabupaten Cilacap, Provinsi Jawa Tengah. Kolokium Hasil Lapangan-DIM. 